\title{
AVALIAÇÃO DE ESPÉCIES PLANTADAS EXPERIMENTALMENTE NA ARBORIZAÇÃO DE RUAS DA CIDADE DE CURITIBA - PR
}

\author{
Daniela Biondi'; ${ }^{1}$ Luciana Leal $^{2}$
}

(recebido em 01.09.2009 e aceito para publicação em 29.12.2009)

\begin{abstract}
RESUMO
O objetivo desta pesquisa foi avaliar o comportamento de espécies plantadas experimentalmente na arborização de ruas da cidade de Curitiba por meio de parâmetros arbóreos quantitativos e qualitativos e da análise das especificações técnicas de plantio e manutenção. Foram amostradas as seguintes espécies: Aleurites fordii Helmsl (tungue), Aspidosperma olivaceum Muell. Arg. (peroba), Citharexylum myrianthum Cham (jacataúva), Clethra scabra Pers. (carne-de-vaca), Holocalyx balansae Miq (alecrim), Jacaranda puberula Cham. (caroba), Michelia champaca Linn. (magnólia-amarela) e Vochysia bifalcata Warm. (guaricica). O local de plantio das árvores foi caracterizado pelos seguintes parâmetros: distância da árvore até o meio-fio, largura da calçada, distância da rede de distribuição de energia, área do canteiro, espaçamento entre árvores. Para cada árvore foram coletados os seguintes parâmetros: altura total da árvore, circunferência à altura do peito, altura da primeira bifurcação, diâmetro da copa, forma da copa, superfície do tronco, alinhamento do tronco, brotação, condições da raiz, e fitossanidade da copa. A avaliação das espécies foi realizada em função das características inerentes a espécies e o seu comportamento nas ruas de Curitiba. A espécie com melhor comportamento foi $C$. scabra $\left(1^{\circ}\right)$, enquanto que as demais foram assim classificadas: $2^{\circ}-A$. fordii, $3^{\circ}-H$. balansae, $4^{\circ}-J$. puberula e $M$. champaca, $5^{\circ}-V$. bifalcata e $6^{\circ}$ - A. olivaceum e C. myrianthum.
\end{abstract}

Palavras-chave: comportamento de espécies, parâmetros qualitativos, parâmetros quantitativos.

\footnotetext{
${ }^{1}$ Engenheira Florestal, Dra., Professora Associada II, Depto. Ciências Florestais, Universidade Federal do Paraná - UFPR, Bolsista Produtividade em Pesquisa - CNPq, Curitiba - PR. E-mail: dbiondi@ufpr.br

${ }^{2}$ Engenheira Florestal, M.Sc. / Companhia Paranaense de Eletricidade - COPEL, Doutoranda em Engenharia Florestal - UFPR. E-mail: luciana.leal@copel.com 


\title{
EVALUATION OF SPECIES USED IN THE ARBORIZATION OF THE STREETS OF CURITIBA CITY, PARANÁ
}

\begin{abstract}
This study aimed to evaluate the behavior of species used in the arborization of the streets of Curitiba City, Paraná State through the evaluation of quantitative and qualitative tree parameters and the analysis of technical specifications of plantation and maintenance. The following species were quantified: Aleurites fordii Helmsl, Aspidosperma olivaceum Muell. Arg., Citharexylum myrianthum Cham, Clethra scabra Pers., Holocalyx balansae Miq, Jacaranda puberula Cham., Michelia champaca Linn. e Vochysia bifalcata Warm. The tree plantation sites were characterized by the tree-curb distance, walkway width, the distance from the power lines, bed area, and the distance between trees. The following tree parameters were determined: total tree height, circumference at breast height, height of the first bifurcation, canopy diameter, canopy shape, trunk surface, trunk alignment, sprouting, root conditions, canopy health. The species were evaluated based on their inherent characteristics and their behavior in the streets of Curitiba City. C. scabra $\left(1^{\circ}\right)$ performed the best, being followed by $2^{\circ}-A$. fordii, $3^{\circ}-H$. balansae, $4^{\circ}-J$. puberula e M. champaca, $5^{\circ}-V$. bifalcata e $6^{\circ}$ - A. olivaceum e C. myrianthum.
\end{abstract}

Keywords: behavior of species, qualitative parameters, quantitative parameters.

\section{INTRODUÇÃO}

A arborização de ruas está inserida num ecossistema ainda desconhecido e sabe-se muito pouco sobre o comportamento de espécies neste meio. Muitas vezes a espécie introduzida assume um comportamento que foge dos padrões esperados, observado no meio natural, como a forma da copa, o tipo de raiz e a susceptibilidade a pragas, doenças e poluição (BIONDI e ALTHAUS, 2005).

No planejamento da arborização de ruas é imprescindível o conhecimento da estrutura urbana para não haver conflito entre árvore e ambiente. Cemig (1996) recomenda uma análise do local, levando-se em conta suas necessidades, limitações, tipo predominante de ocupação, características do tráfego, largura das ruas, tipo de solo e características ambientais. Além destes, também deve se considerar as características da via (expressa, secundária, principal), as instalações, equipamentos e mobiliários urbanos subterrâneos e aéreos, como de água, de esgoto, de eletricidade, cabos, fibras óticas, telefones públicos e placas de sinalização viária/trânsito entre outros, além do recuo das edificações (SÃO PAULO, 2005). 
A única maneira de conhecer o comportamento de espécies arbóreas no meio urbano é plantando árvores em calçadas. Pela complexidade da interação de fatores existentes, infelizmente, não é possível obter informações reais utilizando simulações de ambientes urbanos. Por isso, é que ao se introduzir espécies novas nas vias públicas faz-se necessário um monitoramento para uma futura avaliação do seu desempenho. Segundo Biondi e Althaus (2005), o período de monitoramento de espécies introduzidas deve estar associado ao seu crescimento ou a velocidade de desenvolvimento. O período mais crítico é o estágio inicial da árvore devido à adaptação ao meio urbano. Quando a espécie é totalmente desconhecida em áreas urbanas, o monitoramento deve ser contínuo com avaliações periódicas estabelecidas de cinco em cinco anos ou de 10 em 10 anos.

Para a seleção de árvores de rua é necessário considerar: desenvolvimento, porte, copa (forma, densidade e hábito), floração, frutificação, resistência a pragas, doenças e poluição, ausência de princípios tóxicos e de preferência que sejam nativas (BIONDI, 2004; COBALCHINI, 2004). Phillips (1993) complementa dizendo que além destas características, as árvores precisam ter boa estrutura, ser fortes, não devem ter galhos quebradiços e raízes superficiais, devem ser tolerantes as características do solo urbano, precisar de pouca manutenção e, acima de tudo, serem bonitas o ano todo.

Segundo Gerhold e Salksteder (1982), a incorreta escolha de espécies pode resultar em sérias perdas financeiras e estéticas. Muitas árvores morrem prematuramente ou sofrem injúrias, resultando em excessivos custos de remoção e substituição.

Biondi e Leal (2009a) consideram importante analisar também nas árvores plantadas em calçadas, qualquer pré-disposição da espécie em desenvolver brotação no tronco ou na raiz, porque pode gerar conflitos com os pedestres pela maior ocupação da área do passeio e, conseqüentemente, exige maior manutenção, aumentando assim os custos. Além disso, a eliminação freqüente destas brotações pode ser uma porta de entrada a pragas e doenças pelos cortes deixados.

Quanto à procedência das espécies, geralmente se dá preferência às espécies nativas da região. No paisagismo, o uso de plantas nativas, ao mesmo tempo em que colabora para a preservação da flora local, é capaz de reforçar identidades regionais (HEIDEN et al., 2006).

A cidade Curitiba é conhecida internacionalmente pela quantidade e qualidade da arborização urbana, distribuída principalmente na arborização de ruas e áreas verdes. A cobertura vegetal de Curitiba, em 2004, foi estimada, por Vieira (2006), em 12.994,50 hectares ou 30\% do seu território. Segundo a Secretaria Municipal de Meio Ambiente (SMMA), em 2000 a cidade de Curitiba tinha um total de área verde disponível de $77.901 .198,20 \mathrm{~m}^{2}$ e o índice de cobertura vegetal de 49,08 $\mathrm{m}^{2} /$ habitante. 
A arborização urbana da cidade de Curitiba é composta por 30 parques e bosques, 11 núcleos ambientais, 5 jardins ambientais, 54 largos, 15 eixos de animação, 393 praças e 330 jardinetes (IPPUC, 2009). De acordo com a Secretaria Municipal de Meio Ambiente (SMMA), há aproximadamente 300 mil árvores plantadas em suas vias públicas.

O processo de formação da cidade de Curitiba foi responsável pela substituição da vegetação original - Floresta Ombrófila Mista e Estepe Gramíneo-Lenhosa - por espécies exóticas (BIONDI e LEAL, 2009b). Sendo assim, nas décadas de 1980 e 1990, a Prefeitura Municipal de Curitiba plantou experimentalmente algumas espécies na arborização de ruas, na grande maioria, espécies nativas. Por motivos desconhecidos, estas espécies não foram mais plantadas sem nunca terem sido avaliadas tecnicamente. $\mathrm{Na}$ busca de fornecer informações sobre as espécies e a forma como foram conduzidas nas ruas surgiu à motivação desta pesquisa.

O objetivo desta pesquisa foi avaliar o comportamento de espécies plantadas experimentalmente na arborização de ruas da cidade de Curitiba utilizando tanto parâmetros arbóreos quantitativos e qualitativos quanto análise das especificações técnicas de plantio e manutenção

\section{MATERIAL E MÉTODOS}

Esta pesquisa foi realizada nas ruas da cidade de Curitiba, capital do Estado do Paraná, localizada na região sul do Brasil. Fundada em 1693, ocupa o espaço geográfico de 432,17 km² de área, na latitude $25^{\circ} 25^{\prime} 40^{\prime \prime} \mathrm{S}$ e longitude $49^{\circ} 16^{\prime} 23^{\prime \prime} \mathrm{W}$.

Para este estudo foram amostradas oito espécies - duas exóticas e seis nativas, sendo estas: Aleurites fordii Helmsl (tungue), Aspidosperma olivaceum Muell. Arg. (peroba), Citharexylum myrianthum Cham (jacataúva), Clethra scabra Pers. (carne-de-vaca), Holocalyx balansae Miq (alecrim), Jacaranda puberula Cham. (caroba), Michelia champaca Linn. (magnólia-amarela) e Vochysia bifalcata Warm. (guaricica), num total de 116 indivíduos. O levantamento dos respectivos exemplares ainda existentes nas vias públicas de Curitiba foi realizado em fevereiro e março de 2009.

O número de indivíduos amostrados variou para cada espécie e foi dependente da quantidade de árvores ainda existentes nas vias públicas. Para A. fordii e M. champaca, devido a existência de maior quantidade de árvores plantadas, limitou-se a amostragem em 30 indivíduos selecionados aleatoriamente. Já para C. scabra, J. puberula e V. bifalcata, a amostragem foi pequena ( 3 e 5 indivíduos) devido a maioria das árvores que foram plantadas já terem sido removidas e a inexistência de outras ruas com plantio destas espécies. 
Para cada espécie analisada foram coletadas informações sobre o local de plantio e parâmetros quantitativos e qualitativos das árvores para descrever o seu comportamento no meio urbano.

O local de plantio de cada árvore foi caracterizado pelos seguintes parâmetros, medidos com o uso de trena: Dmf - distância da árvore até o meio-fio, medido do centro do tronco da árvore até o meio-fio em metros; Lc - largura da calçada, medida em metros; Pf distância da rede de distribuição de energia (quando existente), medida do centro da árvore até a fiação em metros, quanto mais próximo de zero tem seu plantio no alinhamento da fiação; Ac - área do canteiro, medida da área livre de pavimentação onde cresce a árvore, em metros quadrados; E - espaçamento entre árvores, em metros, dado coletado quando havia o plantio regular da mesma espécie.

Para cada árvore amostrada foram coletados os seguintes parâmetros dendrométricos, obtidos da seguinte forma: $\mathbf{H}$ - altura total da árvore estimada, em metros; CAP - circunferência à altura do peito, medida com fita métrica, em centímetros; $\mathbf{H b}$ - altura da primeira bifurcação, medida com trena, em metros; Dc - diâmetro da copa, medido longitudinalmente a calçada sob a projeção da copa, em metros.

A partir destes dados, visto que as espécies já se caracterizavam como adultas, elas foram classificadas quanto ao seu porte:

a) Pequeno - na fase adulta podem atingir até $5 \mathrm{~m}$ de altura total, sendo que sua copa é de aproximadamente $2,5 \mathrm{~m}$.

b) Médio - são aquelas cuja altura na fase adulta atinge de 5 a $10 \mathrm{~m}$ e o raio da copa é de 4 a $5 \mathrm{~m}$.

c) Grande - são aquelas que, na fase adulta, ultrapassam 10 m de altura e o raio da copa é superior a $5 \mathrm{~m}$.

Também foram coletados em cada árvore os seguintes parâmetros qualitativos: Cc forma da copa: global; elíptica; colunar; flabeliforme, umbeliforme, irregular, sem copa; St superfície do tronco: lisa; fissurada; áspera; placas; At - alinhamento do tronco: reto, inclinado, tortuoso; $\mathbf{B r}$ - brotação: adventícia e epicórmica; $\mathbf{C r}$ - condições da raiz: sem ocorrência de raiz exposta; exposição de raiz só no canteiro; exposição de raiz na calçada; exposição de raiz em canteiro e calçada; $\mathbf{F}$ - fitossanidade da copa: sadia, insetos, presença de infestação de erva-de-passarinho.

Outras características analisadas para cada espécie, com base nas informações coletadas em loco e referências bibliográficas, foram: densidade e hábito da copa, floração, frutificação (tipo de fruto), resistência a pragas, doenças e poluição, presença de princípios tóxicos e ou alérgicos, presença de acúleos ou espinhos, adaptabilidade climática, grupo 
ecológico sucessional (pioneira, secundária inicial, secundária tardia e clímax), ciclo de vida e rusticidade.

A partir de todas as informações coletadas foram analisadas as espécies que possuem atributos para continuarem sendo indicadas para plantio na arborização viária e aquelas que possuem características inadequadas para este uso. Para isto, foram valorados os pontos positivos apresentados pelas espécies.

A avaliação das espécies foi realizada em função das características inerentes a espécies e o seu comportamento nas ruas de Curitiba. Consideraram-se as especificações técnicas para arborização de ruas - plantio e manejo, conforme Biondi e Althaus (2005), Milano e Dalcin (2000), e as características das espécies por Carvalho (1994), Roderjan e Barddal (1998), Lorenzi (1992 e 1998) e Lorenzi et al. (2003). Também a preferência dos moradores de Curitiba, que segundo Queiroz (2001), as árvores precisam ter porte médio, forma globosa, folhas simples, copa perene, não ser frutífera (comestível), flores de cor rosada e amarela, com floração o ano inteiro ou primavera-verão e plantadas com espaçamento que deixe as copas separadas.

\section{RESULTADOS E DISCUSSÃO}

\section{Análise das Espécies}

Aleurites fordii Helmsl. (Euphorbiaceae), conhecida por tungue e árvore-de-óleoda-china, é uma árvore decídua no inverno, originária da China e Î́ndia. Destaca-se pelo efeito outonal da sua folhagem e outras qualidades como: rápido crescimento, relativa rusticidade e pode ser cultivada em quase todo território brasileiro (LORENZI et al., 2003).

Em Curitiba foram amostrados indivíduos desta espécie com altura que variou de 4 a $7 \mathrm{~m}$ e CAP maior que $56 \mathrm{~cm}$ (Tabela 1). Segundo Roderjan e Barddal (1998) e Lorenzi et al. (2003), a espécie possui porte médio com altura de 6 a $12 \mathrm{~m}$. Isto demonstra que as árvores já estão na fase adulta. A largura da calçada foi maior que 4,68 m (Tabela 3), uma largura satisfatória para este porte. Segundo Cemig (s/d), com esta largura podem ser plantadas até espécies de grande porte.

As árvores amostradas estavam a uma distância do meio-fio maior que 0,66 m (Tabela 3). Sabe-se que quanto menor a distância do meio-fio, maior é a susceptibilidade da árvore aos danos pelos automóveis. Elektro (2002) indica uma distância de 0,50 m.

O espaçamento entre as árvores foi maior que 7,96 m (Tabela 3) e o diâmetro de copa maior que 5,26 m (Tabela 1), isto significa que a copa das árvores não se entrelaçam. Elektro (2002) recomenda o espaçamento de $7 \mathrm{~m}$ entre árvores de médio porte.

Quanto a forma da copa, 53\% apresentaram forma globosa e elíptica, com diâmetro de copa maior que $5 \mathrm{~m}$ (Tabelas 2 e 1). Conforme Lorenzi et al. (2003), esta espécie possui 
forma arredondada e aberta. Sendo assim, mais de $40 \%$ das árvores tiveram uma manutenção inadequada (poda), a qual descaracterizou a forma peculiar da espécie. $O$ motivo de uma poda deformante pode está associado ao plantio da árvore no alinhamento da fiação aérea que tem uma distância que varia de 0,67 a 2,81 m (Tabela 3). Muitas das árvores plantadas exatamente sob o eixo das redes de distribuição de energia têm suas copas sujeitas as podas drásticas. Segundo São Paulo (2005), sob rede elétrica, recomenda-se apenas o plantio de árvores de pequeno porte.

Aspectos fitossanitários, como 100\% de copa sadia (Tabela 2), indicam a sua resistência a pragas e doenças, embora tenha sido constatada a presença de erva-depassarinho em $73 \%$ das árvores amostradas. Este é um fator negativo, já que árvores com alta infestação por erva-de-passarinho têm com freqüência sua taxa de crescimento reduzida, podendo levá-las a um estado de declínio (TATTAR, 1978; CAZETTA e GALLETTI, 2003).

Todas as árvores amostradas apresentaram tronco reto com superfície áspera (Tabela 3), característica específica comprovada por Roderjan e Barddal (1998).

A maioria das árvores (90\%) apresentou raiz pivotante e $10 \%$ com exposição de raízes no canteiro e na calçada. O que contribuiu para a pouca exposição de raiz foi a grande área livre sem ocupação do tronco e pavimento com 6,70 $\mathrm{m}^{2}$ (Tabela 2). A área do canteiro, incluindo o tronco da árvore, variou de 1,00 a $12,52 \mathrm{~m}^{2}$ (Tabela 3). O valor encontrado foi excelente para o desenvolvimento das árvores. Elektro (2002) considera um canteiro ideal com $1 \mathrm{~m}^{2}$.

A altura de bifurcação das árvores amostradas variou de 3,12 a 1,48 m (Tabela 1). Supõe-se que a menor altura de bifurcação, não adequada para árvores de calçadas, que é 1,80 m, seja devido a $100 \%$ de ocorrência de brotação adventícia no tronco (Tabela 2). Outra causa também seria o plantio de mudas sem padrão de qualidade para arborização de ruas.

Outras informações importantes da espécie para o uso nas calçadas são: folhas simples; inflorescência de cor branco-avermelhada e ornamental; frutos do tipo cápsula, deiscentes, de polpa carnosa (LORENZI et al., 2003). O único inconveniente destes pode ser o fruto, principalmente, pela sujeira proveniente da polpa carnosa.

Aspidosperma olivaceum Muell. Arg. (Apocynaceae), conhecida por peroba, peroba-amarela, peroba-vermelha, guatambu, guatambú-peroba, é uma espécie semidecidual (RODERJAN e BARDDAL, 1998), secundária (PARON et al., 2009), nativa da Floresta Estacional Semidecidual. 
Em Curitiba, os indivíduos desta espécie apresentaram altura maior que 5,34 m e CAP maior que 47,7 cm (Tabela 1). De acordo com Roderjan e Barddal (1998), esta espécie é de porte grande, com altura maior que $12 \mathrm{~m}$.

A largura da calçada foi maior que 2,85 m (Tabela 3). CEMIG (s/d) recomenda o plantio de espécies de grande porte em passeios largos $(3,00 \mathrm{~m})$ no lado sem fios ou nos dois lados com fiação subterrânea. A distância da árvore ao meio-fio foi maior que 0,81 m (Tabela 3). Esta distância foi considerada grande, quando comparada com a recomendação de 0,50 m por Elektro (2002) e São Paulo (2005).

O espaçamento entre as árvores foi maior que 7,49 m (Tabela 3) e o maior diâmetro de copa foi de 2,78 m (Tabela 1). Isto indica que as copas das árvores estão separadas. E $50 \%$ das árvores apresentaram copa de forma elíptica e 50\% de forma colunar (Tabela 2). Roderjan e Barddal (1998) afirmam que esta espécie tem forma de copa elíptica. A alteração da forma original da espécie demonstra a manutenção inadequada.

Observa-se que mais de $50 \%$ das árvores (Tabela 2) não apresentaram tronco reto, $50 \%$ com superfície áspera e 50\% com superfície fissurada, concordando com Roderjan e Barddal (1998). Também que $75 \%$ das árvores apresentaram brotação epicórmica. Isto pode ser uma reação às podas realizadas.

Todas as árvores apresentaram raiz pivotante (Tabela 2), embora tivesse a segunda menor área livre sem ocupação do tronco e pavimento com 0,35 $\mathrm{m}^{2}$ (Tabela 3). A área total do canteiro, incluindo o tronco da árvore, variou entre 0,22 a 0,54 $\mathrm{m}^{2}$. Áreas de canteiro bem inferiores ao recomendado por Elektro (2002), que é de $1 \mathrm{~m}^{2}$.

Outras informações importantes da espécie para o uso nas calçadas são: flores de cor verde, fruto tipo folículo e folhas simples (RODERJAN e BARDDAL, 1998); e crescimento lento (PARON et al., 2009). Segundo Ambiente Brasil (2009), esta espécie está na lista de espécies com limitação de uso em arborização urbana por ter crescimento lento.

Citharexyllum myrianthum Cham. (Verbenaceae), popularmente conhecida por jacataúva, tucaneiro (Santa Catarina), pau-de-viola (São Paulo), tucaneira, jacareúba, bagade-tucano, pombeiro, tarumã, tarumã-branco e pau-viola, é uma árvore decídua, heliófila, nativa da Floresta Pluvial Atlântica e Florestas de Galeria; ocorrendo desde a Bahia até o Rio Grande do Sul (LORENZI, 1992).

Em Curitiba, os indivíduos desta espécie apresentaram altura maior que $8 \mathrm{~m}$ e CAP maior que $136 \mathrm{~cm}$ (Tabela 1), demonstrando estar na fase adulta, segundo Lorenzi (1992) e Backes e Irgang (2004). É uma árvore de grande porte. A largura da calçada, maior que 4,10 m, é condizente com o porte da árvore, segundo São Paulo (2005). 
A distância do meio-fio à árvore foi maior que 1,23 m (Tabela 3). Em ruas de grande tráfego, a maior distância do meio evita transtornos da copa da árvore com os automóveis. Com o espaçamento entre as árvores maior que 12,04 m (Tabela 3) e o diâmetro de copa maior que 8,68 m (Tabela 1), o plantio das árvores foram com copas separadas.

$\mathrm{Na}$ Tabela 2 observa-se que a maioria das árvores amostradas (83\%) apresentou forma umbeliforme, conforme Roderjan e Barddal (1998). Este fato demonstra uma manutenção (poda) adequada.

A distância mínima da projeção da fiação aérea até árvore foi de 0,61 m (Tabela (3). Isto indica que as árvores não estão plantadas no alinhamento da fiação aérea. É uma condição favorável para a preservação da forma de copa característica da espécie. Segundo São Paulo (2005), sob rede elétrica é possível o plantio de árvores de grande porte, em calçadas acima de 3,0 m, desde que a muda não seja plantada no alinhamento da rede e que a copa das árvores seja conduzida precocemente, através do trato cultural adequado, acima dessa rede.

Todas as árvores se apresentaram sadias (Tabela 2), mas 50\% das árvores estavam com a presença de erva-de-passarinho.

Todas as árvores amostradas apresentaram tronco reto com superfície fissurada (Tabela 2). Carvalho (1994) e Backes e Irgang (2004) afirmam que esta espécie possui tronco reto ou levemente curvo e geralmente curto. Quanto a superfície do tronco não concorda com as afirmações de Carvalho (1994), que diz ter casca levemente áspera e descamante; enquanto Backes e Irgang (2004) dizem descamar em placas irregulares de baixo para cima.

Mais de $30 \%$ das raízes se encontravam expostas no canteiro da árvore (Tabela 2). Este fato pode estar associado a falta de cobertura do canteiro que o torna compactado pelo pisoteio e/ou com a perda de solo. Observa-se na Tabela 3, que em média, há espaço sem ocupação do tronco no canteiro com 1,73 $\mathrm{m}^{2}$ para a realização das necessidades vitais das raízes. A área do canteiro, incluindo o tronco, teve uma variação muito grande, variou de 0 a $4,10 \mathrm{~m}^{2}$. Isto indica que algumas árvores não tinham canteiro para o seu desenvolvimento.

A altura de bifurcação variou de 2,16 a 3,64 m, bem acima do recomendado, embora todas as árvores tenham apresentado brotações adventícias no tronco e epicórmicas estimuladas por podas (Tabelas 1 e 2). Este bom desempenho pode ser resultado da sua manutenção no meio urbano.

Todas as árvores apresentaram tanto brotação adventícia no tronco como brotação epicórmica (Tabela 2), provavelmente, uma característica da espécie. Segundo Carvalho (1994), esta espécie possui caracteristicamente crescimento irregular com emissão de 
brotação desde a base e presença de multitroncos, apresenta brotação após o corte e necessita poda de condução.

Outras informações importantes da espécie para o uso nas calçadas: folhas simples, face interior de coloração mais clara, madeira de baixa durabilidade, principalmente quando exposta; flores são melíferas; frutos são muito apreciados por várias espécies de pássaros; rápido crescimento; mudas com rápido desenvolvimento no campo podendo atingir $4 \mathrm{~m}$ de altura aos 2 anos (LORENZI, 1992); frutos ornamentais de cor vermelha quando maduros, do tipo drupa esférico com $1 \mathrm{~cm}$ de diâmetro, fácil propagação por sementes, estaquia e broto de raízes (BACKES e IRGANG, 2004); flores de coloração creme, fruto é uma baga (RODERJAN e BARDDAL,1998).

Clethra scabra Pers. (Clethraceae), conhecida por caujuja, guaperê, carne-de-vaca, vassourão (São Paulo), pau-de-cinzas, peroba-brava e peroba-café; é uma planta semidecídua, heliófila, seletiva xerófita e pioneira; nativa da Floresta Pluvial Atlântica e Semidecídua de Altitude (LORENZI, 1998).

Em Curitiba, as árvores amostradas apresentaram altura que variou de 2,62 a 10,04 m e CAP maior que $26 \mathrm{~cm}$ (Tabela 1). Pode atingir a altura de 4 a $8 \mathrm{~m}$ (LORENZI, 1998). É uma espécie de médio porte.

A largura da calçada foi maior que 4,03 m (Tabela 6). De acordo com CEMIG (s/d) e São Paulo (2005), esta largura é suficiente até para uma espécie de grande porte. A distância da árvore ao meio-fio foi maior que 0,83 m (Tabela 3). Em comparação com as recomendações de Elektro (2002), que é de 0,50 m, é considerada uma grande distância.

Todos os indivíduos apresentaram copa de forma elíptica e o estado fitossanitário sadio, tronco reto e liso (Tabela 2). Estes aspectos divergem dos encontrados por Lorenzi (1998), tais como: copa irregular e densa, tronco tortuoso, ramificado, com casca rugosa nos indivíduos mais velhos. E concordam com Roderjan e Barddal (1998), quanto a forma da copa.

$\mathrm{Na}$ Tabela 2 observa-se que $67 \%$ das árvores apresentaram raiz pivotante e $33 \%$ com exposição de raiz apenas no canteiro. Esta pequena percentagem de exposição de raiz pode está associada à falta de solo no canteiro já que o mesmo possui 1,55 $\mathrm{m}^{2}$ de área livre sem ocupação do tronco e pavimento (Tabela 3). Além disso, a grande variação da área do canteiro incluindo o tronco da árvore $\left(0\right.$ a 3,92 $\left.\mathrm{m}^{2}\right)$ demonstrou que algumas árvores não apresentaram nenhuma área de canteiro.

Mais de 30\% das árvores apresentaram brotação adventícia no tronco e brotações epicórmicas (Tabela 2). 
Outras informações importantes da espécie para o uso nas calçadas são: folhas simples, madeira de baixa resistência mecânica e pouca durabilidade, árvore rústica e de crescimento rápido (LORENZI, 1998); fruto cápsula com $4 \mathrm{~mm}$ de diâmetro (BACKES e IRGANG, 2004); flor de bege e com hábito de copa semidecidual (RODERJAN e BARDDAL, 1998).

Holocalyx balansae Miq. (Caesalpinaceae), conhecida popularmente por alecrim, ibiraperê, uirapepê, alecrim-de-campinas e pau-alecrim, é uma planta semidecídua, ombrófila clímax da floresta pluvial subtropical, ocorre de São Paulo até o Rio Grande do Sul (LORENZI, 1992).

As árvores amostradas em Curitiba apresentaram altura que variou de 4,95 a 8,67 m e CAP maior que $86 \mathrm{~cm}$ (Tabela 1). Segundo Lorenzi (1992), esta espécie pode atingir a altura de 15 a 25 m e 50 a 80 cm de diâmetro. É uma espécie de grande porte.

A largura da calçada foi maior que 2,81 m (Tabela 3). De acordo com o porte da espécie, é um valor que está inserido nas recomendações da CEMIG (s/d). A distância da árvore ao meio-fio foi maior que $1 \mathrm{~m}$. De acordo com Elektro (2002) é uma distância bem acima do recomendado $(0,50 \mathrm{~m})$.

A distância da projeção da fiação aérea foi maior que 0,50 m (Tabela 3). Isto indica que a projeção da fiação não está no centro da árvore, mas assim mesmo, há necessidade de poda de condução o que poderá interferir na forma da copa da árvore.

O espaçamento entre as árvores foi maior que $12,38 \mathrm{~m}$ e o diâmetro de copa foi maior que $6,08 \mathrm{~m}$, consequentemente, é um plantio com copas separadas.

Mais de 50\% das árvores apresentaram forma elíptica e 42\% copa irregular (Tabela 2), formas diferentes da forma globosa que foram descritas por Lorenzi (1992), Roderjan e Barddal (1998) e Carvalho (1994). A deformação da copa é o produto da manutenção inadequada, com a realização de podas sem respeitar a forma original da espécie. A copa das árvores atingiu um diâmetro médio de 8,35 m (Tabela 1), embora esta medida não seja real por causa das podas, ainda é um valor acima da média indicada por Carvalho (1994) que é de $6 \mathrm{~m}$.

Todas as árvores apresentaram copas sadias, porém com a ocorrência de erva-depassarinho (15\%). Possui tronco reto com descamação em placas (Tabela 2). Este fato atesta a maturidade das árvores porque segundo Carvalho (1994), esta espécie apresenta casca lisa quando jovem e fissurada e placas quando velha.

A altura de bifurcação foi superior a 1,70 m (Tabela 1), não concordando com Carvalho (1994) que afirma ter tronco curto. Esta performance adquirida pode ser produto 
de tratos culturais na formação de mudas e manutenção das árvores adultas com podas de condução.

Quanto a raiz, mais de $80 \%$ apresentou pivotante (Tabela 2), apesar de ter 0,45 $\mathrm{m}^{2}$ de área livre sem ocupação do tronco e pavimento (Tabela 3), que parece muito pouco para o porte da árvore. A área do canteiro incluindo o tronco variou de 0,07 a 1,01 $\mathrm{m}^{2}$, demonstrando que muitas árvores não tinham uma área adequada, segundo São Paulo (2005), que é de 3,0 $\mathrm{m}^{2}$ para árvores de copa grande, em torno de 8,0 $\mathrm{m}$.

A brotação epicórmica foi predominante (84\%), podendo ser uma característica da espécie ou reação às podas realizadas (Tabela 2).

Outras informações importantes da espécie para o uso nas calçadas são: folhas tóxicas, frutos muito apreciados por morcegos, madeira com longa durabilidade, copa perene e densa, capaz de proporcionar ótima sombra, lento crescimento, produção de mudas lenta e seu desenvolvimento também (LORENZI, 1992); fruto drupa, folhas compostas e pinadas (RODERJAN e BARDDAL, 1998); espécie esciófila, necessitando de sombreamento moderado na fase juvenil, carece de podas periódicas para a condução e dos galhos, crescimento sem dominância apical, com tronco curto, madeira com extraordinária resistência e durabilidade, fruto do tipo drupa amarela carnosa indeiscente com 1 a 3 cm de diâmetro, e poder germinativa de 50 a 80\% (CARVALHO, 1994).

Jacaranda puberula Cham. (Bignoniaceae), conhecida popularmente por carobinha, jacarandá-branco, caroba-da-mata, caroba, carobeira, caroba-roxa, caroba-do-campo, caroba-miúda, caroba-pequena, caroba-brava e pau-de-colher, é uma planta decídua, heliófila, ocorrendo tanto no interior da floresta como em formações secundárias, do Rio de Janeiro ao Rio Grande do Sul (LORENZI, 1992).

As árvores amostradas em Curitiba apresentaram altura entre 3,57 a 5,24 m com CAP maior que $34 \mathrm{~cm}$ (Tabela 1). A altura pode atingir de 4 a $7 \mathrm{~m}$ de altura e 30 a $40 \mathrm{~cm}$ de diâmetro (LORENZI, 1992). A espécie é de porte pequeno a médio.

A largura da calçada foi maior que 3,39 m (Tabela 3), sendo um valor adequado com o porte, segundo CEMIG (s/d). A distância da árvore ao meio-fio foi maior que 1,03 m. Pelo porte da espécie, esta distância pode ser considerada excelente porque excede muito o valor recomendado por Elektro (2002). No entanto, a distância da projeção da fiação aérea foi de apenas $0,23 \mathrm{~m}$.

O espaçamento entre as árvores foi maior que $8,14 \mathrm{~m}$ e o diâmetro de copa foi maior que 2,82 m, consequentemente, é um plantio com copas separadas. Elektro (2002) recomenda um espaçamento de $7 \mathrm{~m}$ para este porte. Todas as árvores apresentaram forma globosa de copa e sadia (Tabela 2), concordando com Roderjan e Barddal (1998). 
$\mathrm{Na}$ Tabela 2 observa-se que 60\% das árvores apresentaram tronco reto e com superfície áspera, também concordando com Roderjan e Barddal (1998).

Quanto a raiz, 100\% das árvores apresentaram raiz pivotante (Tabela 2), embora apresente a menor área livre sem ocupação do tronco e pavimento com 0,27 $\mathrm{m}^{2}$ (Tabela 3). A área de canteiro, incluindo o tronco, variou de 0,19 a 0,39 $\mathrm{m}^{2}$, valores muito inferiores ao recomendado de $1 \mathrm{~m}^{2}$.

Das árvores avaliadas, 40\% apresentaram brotação epicórmica (Tabela 2), provavelmente, deve ser uma resposta às podas feitas.

Outras informações importantes da espécie para o uso nas calçadas são: folha composta (bipinada), flor rosada, fruto silíqua (RODERJAN e BARDDAL, 1998); rápido crescimento (GLUFKE, 1999); madeira tem pouca resistência ao apodrecimento; bastante ornamental, podendo ser empregada com sucesso no paisagismo, principalmente, na arborização de ruas estreitas e sob redes elétricas (LORENZI, 1992).

Michelia champaca Linn. (Magnoliaceae), conhecida por magnólia-amarela e champá, é uma árvore perenifólia originária da Îndia e Himalaia (LORENZI et al., 2003).

Em Curitiba as árvores amostradas apresentaram altura que variou de 3,83 a 8,45 m e CAP maior que $57 \mathrm{~cm}$ (Tabela 1). Pode atingir a altura de 7 a $10 \mathrm{~m}$ (LORENZI et al., 2003) ou de 6 a 12 m de altura (RODERJAN e BARDDAL, 1998). Possui porte médio.

De acordo com o porte da espécie, a largura da calçada (maior que $5 \mathrm{~m}$ ) foi considerada muito além do recomendado (Tabela 3). O mesmo acontece com a distância da árvore ao meio-fio que foi maior que $1,15 \mathrm{~m}$.

O espaçamento entre as árvores foi maior que $6,35 \mathrm{~m}$ e o diâmetro de copa foi maior que 3,41 m, consequentemente, é um plantio com copas separadas.

Observa-se na Tabela 2 que as árvores apresentaram diversas formas de copa, tais como: globosa (30\%), elíptica (30\%), colunar (20\%), flabeliforme (3\%), irregular $(7 \%)$ e sem copa (10\%). Provavelmente estas diferentes formas são resultados das podas realizadas. É considerada árvore de copa muito ornamental, principalmente por sua uniformidade piramidal na juventude (LORENZI et al., 2003) e de forma cônica por Roderjan e Barddal (1998).

Foram observadas podas drásticas em árvores nas calçadas sem fiação aérea. De acordo com a Tabela 2, 10\% das árvores amostradas estavam sem copa pela poda. E mesmo em calçadas com fiação aérea, as podas drásticas realizadas não se justificavam porque a distância da projeção da fiação até a árvore foi maior que 0,8 $\mathrm{m}$ (Tabela 3). Este valor indica que a fiação aérea não estava no alinhamento da árvore. Além dessa distância, a forma cônica da copa ajuda a ter menos possibilidade de podas drásticas. 
Todas as árvores apresentaram copa sadia com tronco reto e liso, que discorda dos autores Roderjan e Barddal (1998) que dizem ter casca áspera com lenticelas. Mais de 20\% das árvores apresentaram erva-de-passarinho (Tabela 2).

O comportamento das raízes (Tabela 2) foi bem diversificado, apresentando raiz pivotante (27\%), raiz exposta só no canteiro da árvore (13\%), raiz exposta só na calçada (37\%) e raízes expostas no canteiro e na calçada (23\%). Isto pode estar refletindo obstáculos subterrâneos porque no canteiro existe uma quantidade razoável de área livre sem ocupação do tronco e pavimento de 1,23 $\mathrm{m}^{2}$ (Tabela 3).

Outras informações importantes da espécie para o uso nas calçadas são: folhas simples de cor verde-claras, frutos na forma de cápsulas coriáceas, deiscentes, sementes apreciadas por pássaros, é uma das espécies mais cultivadas nas ruas das cidades do norte do Paraná (LORENZI et al., 2003); folhas persistentes (RODERJAN e BARDDAL, 1998); e rápido crescimento (JBRJ, 2009).

Vochysia bifalcata Warm. (Vochysiaceae), conhecida por guaricica, pau-de-vinho, vinheiro, pau-amarelo e canela-santa, é uma planta perenifólia, heliófila ou de luz difusa da Floresta Pluvial da encosta Atlântica e planície litorânea, ocorrendo em São Paulo e Rio de Janeiro (LORENZI, 1998).

As árvores amostradas em Curitiba apresentaram altura entre 10,57 a 13,93 m com CAP maior que $57 \mathrm{~cm}$ (Tabela 1). Pode chegar a altura de 7 a $24 \mathrm{~m}$ e 40 a $60 \mathrm{~cm}$ de diâmetro (LORENZI, 1998). Esta espécie possui porte médio.

A largura da calçada foi maior que 6,48 m (Tabela 6). De acordo com a CEMIG (s/d) esta largura é o dobro que se recomenda para o porte desta espécie. Da mesma forma acontece com a distância da árvore ao meio-fio, que foi maior que 3,31 m.

O espaçamento entre as árvores foi maior que 3,44 m (Tabela 3) e o diâmetro de copa foi maior que $8,62 \mathrm{~m}$ (Tabela 1), consequentemente, é um plantio com copas entrelaçadas.

Todas as árvores apresentaram copa de forma elíptica (Tabela 2), discordando de Roderjan e Barddal (1998) que a consideram umbeliforme. Isto pode ser resultado de podas deformantes ou interpretação dos autores.

O tronco das árvores foram todos retos de superfície fissurada (Tabela 2), concordando com Roderjan e Barddal (1998) e Carvalho (1994).

As raízes apresentaram-se expostas só no canteiro (40\%) e exposta só na calçada (60\%). Este comportamento pode estar exprimindo a característica da espécie no meio urbano, já que a área livre do canteiro foi de $24,58 \mathrm{~m}^{2}$ (Tabela 3). A área do canteiro, incluindo o tronco da árvore, apresentou valores muito altos, variando de 14,85 a 34,91 $\mathrm{m}^{2}$. 
Todas as árvores amostradas apresentaram brotação epicórmica (Tabela 2), provavelmente, é uma reação às podas severas. Segundo Carvalho (1994), esta espécie apresenta brotação em touça após o corte.

Outras informações importantes da espécie para o uso nas calçadas são: fruto cápsula deiscente de cor verde brilhante, madeira com baixa resistência mecânica e muito susceptível ao apodrecimento, árvore é bastante ornamental quando em flor, podendo ser usada na arborização de parques e grandes jardins (LORENZI, 1998); folha simples e persistente (RODERJAN e BARDDAL, 1998); tolera sombreamento na fase juvenil, espécie apícola, flores amarelas, vistosas reunidas em cacho, poder germinativo baixa (22 a 40\%), apresenta crescimento monopodial com ramificação leve e rápido crescimento (CARVALHO, 1994).

Tabela 1 - Parâmetros arbóreos quantitativos das espécies na arborização de ruas de Curitiba, 2009

\begin{tabular}{|l|c|c|c|c|}
\hline \multicolumn{1}{|c|}{ Espécie } & $\mathrm{H}(\mathrm{m})$ & $\mathrm{Hb}(\mathrm{m})$ & $\mathrm{CAP}(\mathrm{cm})$ & $\mathrm{Dc}(\mathrm{m})$ \\
\hline Aleurites fordii. & $5,61 \pm 1,39$ & $2,30 \pm 0,82$ & $84,48 \pm 28,04$ & $7,49 \pm 2,23$ \\
\hline Aspidosperma olivaceum & $6,02 \pm 0,68$ & $2,82 \pm 0,72$ & $62,00 \pm 14,30$ & $4,02 \pm 1,24$ \\
\hline Citharexylum myrianthum & $10,84 \pm 2,41$ & $2,90 \pm 0,74$ & $172,08 \pm 35,90$ & $12,94 \pm 4,26$ \\
\hline Clethra scabra & $6,33 \pm 3,71$ & $2,10 \pm 1,60$ & $53,33 \pm 27,30$ & $5,18 \pm 0,81$ \\
\hline Holocalyx balansae & $6,81 \pm 1,86$ & $2,00 \pm 0,27$ & $108,00 \pm 21,55$ & $8,35 \pm 2,27$ \\
\hline Jacaranda puberula & $4,45 \pm 0,79$ & $1,69 \pm 0,59$ & $46,80 \pm 12,91$ & $4,66 \pm 1,84$ \\
\hline Michelia champaca & $6,14 \pm 2,31$ & $2,19 \pm 0,67$ & $81,8 \pm 24,28$ & $6,04 \pm 2,63$ \\
\hline Vochysia bifalcata & $12,25 \pm 1,68$ & $2,74 \pm 0,62$ & $193,80 \pm 53,69$ & $11,39 \pm 2,77$ \\
\hline
\end{tabular}

Legenda: $\mathbf{H}=$ altura da árvore; $\mathbf{H b}=$ altura de bifurcação; $\mathbf{C A P}=$ circunferência a altura do peito; $\mathbf{D c}=$ diâmetro de copa.

Tabela 2 - Parâmetros arbóreos qualitativos das espécies na arborização de ruas de Curitiba, 2009

\begin{tabular}{|c|c|c|c|c|c|c|c|c|c|}
\hline \multicolumn{2}{|c|}{ PARÂMETROS QUALITATIVOS/ESPÉCIES } & 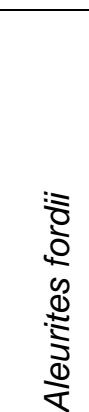 & 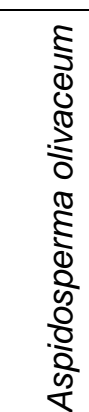 & 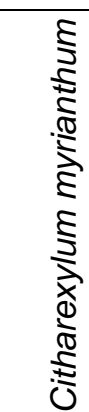 & 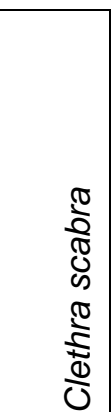 & 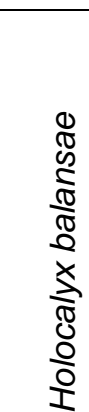 & 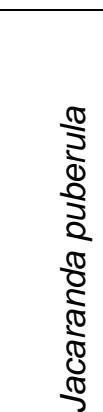 & 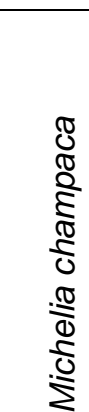 & 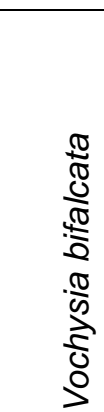 \\
\hline \multirow[t]{4}{*}{ Cc -Forma da copa } & Globosa & $23 \%$ & & & & $5 \%$ & $100 \%$ & $30 \%$ & \\
\hline & Elíptica & $30 \%$ & $50 \%$ & $17 \%$ & $100 \%$ & $53 \%$ & & $30 \%$ & $100 \%$ \\
\hline & Colunar & & $50 \%$ & & & & & $20 \%$ & \\
\hline & Flabeliforme & & & & & & & $3 \%$ & \\
\hline
\end{tabular}




\begin{tabular}{|c|c|c|c|c|c|c|c|c|c|}
\hline & Umbeliforme & & & $83 \%$ & & & & & \\
\hline & Irregular & $47 \%$ & & & & $42 \%$ & & $7 \%$ & \\
\hline & Sem copa & & & & & & & $10 \%$ & \\
\hline & Sadia & $100 \%$ & $98 \%$ & $100 \%$ & $100 \%$ & $100 \%$ & $100 \%$ & $100 \%$ & $100 \%$ \\
\hline F - Fitossanidade & Inseto & & $2 \%$ & & & & & & \\
\hline & Erva-de-passarinho & $73 \%$ & & $50 \%$ & & $16 \%$ & & $23 \%$ & \\
\hline & Liso & & & & $100 \%$ & & & $100 \%$ & \\
\hline Ct Tronon & Fissurado & & $50 \%$ & $100 \%$ & & & & & $100 \%$ \\
\hline St-1ronco & Áspera & $100 \%$ & $50 \%$ & & & & $60 \%$ & & \\
\hline & Placas & & & & & $100 \%$ & $40 \%$ & & \\
\hline & Reto & $100 \%$ & $42 \%$ & $100 \%$ & $100 \%$ & $100 \%$ & $60 \%$ & $100 \%$ & $100 \%$ \\
\hline At - Alinhamento & Inclinado & & $50 \%$ & & & & $20 \%$ & & \\
\hline & Tortuoso & & $8 \%$ & & & & $20 \%$ & & \\
\hline & Pivotante & $90 \%$ & $100 \%$ & $8 \%$ & $67 \%$ & $84 \%$ & $100 \%$ & $27 \%$ & \\
\hline $\mathrm{Cr}-\mathrm{Raiz}$ & Raiz exposta - canteiro & $7 \%$ & & $33 \%$ & $33 \%$ & $5 \%$ & & $13 \%$ & $40 \%$ \\
\hline Cr - Ralz & Raiz exposta -calçada & $3 \%$ & & & & $5 \%$ & & $37 \%$ & $60 \%$ \\
\hline & Raiz exposta - canteiro e calçada & & & $58 \%$ & & $5 \%$ & & $23 \%$ & \\
\hline & Adventícia & $100 \%$ & & & & & & & \\
\hline $\mathrm{Br}$ - Brotação & Epicórmica & & $75 \%$ & & & $84 \%$ & $40 \%$ & $100 \%$ & $100 \%$ \\
\hline & Adventícia/epicórmica & & & $100 \%$ & $33 \%$ & $5 \%$ & & & \\
\hline
\end{tabular}

Tabela 3 - Especificação de plantio das espécies na arborização de ruas de Curitiba, 2009

\begin{tabular}{|l|c|c|c|c|c|c|}
\hline Espécie & $\mathrm{Dmf}(\mathrm{m})$ & $\mathrm{Lc}(\mathrm{m})$ & $\mathrm{Pf}(\mathrm{m})$ & $\mathrm{E}(\mathrm{m})$ & $\mathrm{Ac}\left(\mathrm{m}^{2}\right)$ & $\begin{array}{c}\mathrm{ALc} \\
\left(\mathrm{m}^{2}\right)\end{array}$ \\
\hline Aleurites fordii . & $0,94 \pm 0,28$ & $5,11 \pm 0,43$ & $1,74 \pm 1,07$ & $14,89 \pm 6,93$ & $6,76 \pm 5,76$ & 6,70 \\
\hline $\begin{array}{l}\text { Aspidosperma } \\
\text { livaceum }\end{array}$ & $0,91 \pm 0,10$ & $3,75 \pm 0,90$ & $\mathrm{X}$ & $14,4 \pm 6,91$ & $0,38 \pm 0,16$ & 0,35 \\
\hline $\begin{array}{l}\text { Citharexylum } \\
\text { myrianthum }\end{array}$ & $1,37 \pm 0,14$ & $4,10+0,00$ & $0,87 \pm 0,26$ & $22,42 \pm 10,38$ & $1,97 \pm 2,13$ & \\
\hline Clethra scabra & $1,00 \pm 0,17$ & $4,54 \pm 0,51$ & $\mathrm{X}$ & $\mathrm{X}$ & $1,77 \pm 2,15$ & 1,73 \\
\hline Holocalyx balansae & $1,12 \pm 0,12$ & $2,86 \pm 0,05$ & $0,65 \pm 0,15$ & $20,36 \pm 7,98$ & $0,54 \pm 0,47$ & 0,45 \\
\hline & & & & & \\
Jacaranda puberula & $2,30 \pm 1,27$ & $3,77 \pm 0,38$ & $0,47 \pm 0,24$ & $8,14 \pm 0,00$ & $0,29 \pm 0,10$ & 0,27 \\
\hline Michelia champaca & $1,34 \pm 0,19$ & $5,00 \pm 0,00$ & $0,95 \pm 0,15$ & $12,8 \pm 6,45$ & $1,28 \pm 1,33$ & 1,23 \\
\hline Vochysia bifalcata & $3,39 \pm 0,08$ & $6,48 \pm 0,00$ & $\mathrm{X}$ & $8,66 \pm 5,22$ & $24,88 \pm 10,03$ & 24,58 \\
\hline
\end{tabular}

Legenda: $\mathbf{D m f}=$ distância da árvore ao meio-fio; $\mathbf{L C}=$ largura da calçada; $\mathbf{P f}=$ projeção da fiação na árvore; $\mathbf{E}=$ espaçamento entre as árvores da mesma espécie; $\mathbf{A c}=$ área do canteiro; $\mathbf{A L c}=$ área livre do canteiro (área do canteiro - área do tronco).

\section{Avaliação das Espécies}

Pode-se observar que não houve muitas discrepâncias na valoração final das espécies analisadas (Tabela 4). Clethra scabra foi a espécie melhor avaliada (nove pontos positivos dos 12 parâmetros analisados). Em seguida, empatadas com oito pontos positivos, vieram: Aleurites forddi, Holocalyx balansae, Jacaranda puberula e Michelia champaca. Enquanto que, Aspidosperma olivaceum e Vochysia bifalcata foram as espécies menos valoradas, contabilizando apenas cinco pontos.

Tabela 4. Avaliação do desempenho das espécies na arborização de ruas de Curitiba, 2009

\begin{tabular}{|l|l|l|l|l|l|l|l|l|l|l|l|l|l|}
\hline Nome popular & Pt & $\begin{array}{c}\text { Hb* } \\
(\mathbf{m})\end{array}$ & Fc & Hc & Tf & Cf & C & At $^{*}$ & $\mathbf{R}^{*}$ & $E^{*}$ & $F^{*}$ & $B^{*}$ & $\begin{array}{c}\text { Pontos } \\
\text { Positivos }\end{array}$ \\
\hline
\end{tabular}




\begin{tabular}{|c|c|c|c|c|c|c|c|c|c|c|c|c|c|}
\hline Aleurites fordii & $\mathrm{M}$ & 2,30 & $G$ & $\mathrm{D}$ & $\mathrm{S}$ & $\mathrm{B}$ & $\mathrm{R}$ & $\mathrm{R}$ & $\mathrm{P}$ & $\mathrm{S}$ & S/E & A & ++++++++ \\
\hline $\begin{array}{l}\text { Aspidosperma } \\
\text { olivaceum }\end{array}$ & G & 2,82 & $E$ & SD & $\mathrm{S}$ & V & $\mathrm{L}$ & I & $\mathrm{P}$ & $\mathrm{S}$ & S & $E$ & +++++ \\
\hline $\begin{array}{l}\text { Citharexylum } \\
\text { myrianthum }\end{array}$ & G & 2,90 & $U$ & D & $\mathrm{S}$ & C & $\mathrm{R}$ & $\mathrm{R}$ & $\mathrm{S}$ & $\mathrm{S}$ & S/E & $\begin{array}{l}E / \\
A\end{array}$ & ++ \\
\hline Clethra scabra & $\mathrm{M}$ & 2,10 & $E$ & SD & $\mathrm{S}$ & A & $\mathrm{R}$ & $\mathrm{R}$ & $\mathrm{P}$ & $\mathrm{X}$ & $\mathrm{S}$ & $x$ & +++++++++ \\
\hline Holocalyx balansae & $\mathrm{G}$ & 2,00 & G & $\mathrm{P}$ & $\mathrm{C}$ & $A$ & $\mathrm{~L}$ & $\mathrm{R}$ & $\mathrm{P}$ & $\mathrm{S}$ & $\mathrm{S}$ & $E$ & ++++++++ \\
\hline Jacaranda puberula & $\mathrm{P}$ & 1,69 & G & D & C & $\mathrm{R}$ & $\mathrm{R}$ & $\mathrm{R}$ & $\mathrm{P}$ & $\mathrm{S}$ & $\mathrm{S}$ & $\mathrm{X}$ & ++++++++ \\
\hline Michelia champaca & $\mathrm{M}$ & 2,19 & $\mathrm{C}$ & $P$ & $\mathrm{~S}$ & $\mathrm{C}$ & $\mathrm{R}$ & $\mathrm{R}$ & $\mathrm{S}$ & $\mathrm{S}$ & $\mathrm{S}$ & $E$ & ++++++++ \\
\hline $\begin{array}{l}\text { Vochysia } \\
\text { bifalcata }\end{array}$ & G & 2,74 & U & $\mathrm{P}$ & $\mathrm{S}$ & A & $\mathrm{R}$ & $\mathrm{R}$ & S & $\mathrm{E}$ & $\mathrm{S}$ & $\mathrm{E}$ & +++++++ \\
\hline
\end{tabular}

LEGENDA: $\mathbf{P t}=$ porte $(\mathrm{G}=$ grande, $\mathrm{M}=$ médio, $\mathrm{P}=$ pequeno); $\mathbf{H b}=$ altura de bifurcação; $\mathrm{Fc}=$ forma de copa ( $\mathrm{G}=$ globosa, $\mathrm{E}=$ elíptica, $\mathrm{U}=$ umbeliforme, $\mathrm{C}=$ cônica); $\mathrm{Hc}=$ hábito da copa ( $\mathrm{P}=$ perene, $\mathrm{S}$ = semidecídua, $\mathrm{D}=$ decídua); $\mathbf{T f}=$ tipo de folha $(\mathrm{S}=$ simples, $\mathrm{C}=$ composta); $\mathbf{C f}=$ cor da floração $(\mathrm{B}=$ branca, $\mathrm{V}=$ verde, $\mathrm{A}=$ amarela, $\mathrm{R}=$ rosa, $\mathrm{C}=$ creme $) ; \mathrm{C}=$ crescimento $(\mathrm{R}=$ rápido, $\mathrm{L}=$ lento); $\mathbf{A t}=$ alinhamento do tronco $(\mathrm{R}=$ reto, $\mathrm{I}=$ inclinado, $\mathrm{T}=$ tortuoso $) ; \mathbf{R}=$ raiz $(\mathrm{P}=$ pivotante, $\mathrm{S}=$ superficial $) ; \mathbf{E}$ = espaçamento $(S=$ separada, $E=$ entrelaçada); $\mathbf{F}=$ fitossanidade $(S=$ sadia, $E$ = erva-depassarinho, I = inseto); $\mathbf{B}$ = brotação ( $\mathrm{A}=$ adventícia, $\mathrm{E}$ = epicórmica).

*Informações provenientes da pesquisa; Células em cinza = pontos positivos.

Quando se analisa os pontos negativos da C. scabra, forma (elíptica) e hábito da copa (semidecidual) observa-se que são parâmetros inerentes à espécie, isto é, não podem ser contornados ou alterados na produção de mudas ou manutenção, como o caso da baixa altura de bifurcação encontrada em J. puberula. Quanto à forma da copa, tanto a forma elíptica como a globosa, são as mais recomendadas para as árvores de ruas, de acordo com Biondi e Althaus (2005). Já o hábito de copa semidecidual, não é um parâmetro que afeta tecnicamente o plantio nas ruas, apenas não atende as preferências dos moradores de Curitiba, segundo Queiroz (2001). Portanto, a boa avaliação da carne-de-vaca pode ser facilmente validada pelos poucos inconvenientes apresentados.

Os pontos negativos de $A$. olivaceum foram: porte (grande), forma da copa (elíptica), hábito da copa (semidecidual), cor da floração (verde), crescimento (lento), alinhamento do tronco (inclinado) e brotação (epicórmica). Dentre estes, os parâmetros técnicos que limitam o plantio desta espécie nas ruas são: grande porte - que exige ruas largas, ausência de fiação, recuo das casas e do meio fio; crescimento lento - que deixa a muda ou árvore vulnerável ao vandalismo; tronco inclinado - prejudica a acessibilidade do passeio e; brotação epicórmica - exige maior manutenção, aumentando assim os custos. Os demais pontos negativos estão relacionados com a preferência dos moradores de Curitiba.

Os pontos negativos de Citharexylum myrianthum foram os seguintes: porte (grande), forma da copa (umbeliforme), hábito da copa (decídua), cor da floração (creme), raiz (superficial), fitossanidade (presença de erva-de-passarinho), brotação (epicórmica e adventícia). Tecnicamente, os parâmetros que limitam seu plantio são: porte grande - item discutido acima; raiz superficial - gera danos às calçadas e possíveis acidentes com 
pedestres; a presença de erva-de-passarinho - demonstra uma susceptibilidade a este hemiparasita que pode afetar o aspecto estético e fisiológico da árvore; brotação epicórmica - item abordado acima; brotação adventícia - ramos no tronco ou raiz exige freqüente manutenção e sua eliminação pode ser uma porta de entrada a pragas e doenças pelos cortes deixados. Assim como em Aspidosperma olivaceum, os outros parâmetros se referem a preferência dos moradores de Curitiba.

Embora o parâmetro - se a espécie é frutífera - não tenha sido avaliado, constatouse que todas as espécies não têm frutos comestíveis, mas em geral, seus frutos são apreciados pelos pássaros. Elektro (2002) não recomenda o plantio de árvores frutíferas comerciais nas vias públicas, porém diz que é desejável o plantio de frutas silvestres para atrair e alimentar pássaros.

Além disso, constatou-se também que todas as oito espécies analisadas apresentavam floração na primavera ou no verão, outro aspecto desejado pelos moradores, segundo Queiroz (2002).

Diante das justificativas apresentadas, verifica-se que os parâmetros utilizados nesta pesquisa serviram para uma boa avaliação das espécies. Com a análise das especificações técnicas de cada espécie constatou-se que o planejamento de plantio referente à largura de calçada, distância de meio-fio e espaçamento, de todas as árvores atendeu aos padrões recomendados pelos manuais de arborização. A especificação de plantio relativa à posição ou o alinhamento da fiação aérea com a árvore, observada através do parâmetro "projeção da fiação aérea", não foi levada em consideração. E também não foi levado em conta o porte das árvores com a presença da fiação aérea nas calçadas. Em conseqüência desta falha no planejamento, algumas espécies sofreram podas que favoreceram a descaracterização de suas copas.

\section{CONCLUSÕES}

De acordo com os resultados obtidos pode-se concluir que o uso de parâmetros arbóreos (quantitativos e qualitativos) e a análise das especificações técnicas de plantio e manutenção foram fundamentais para a avaliação das espécies.

Os parâmetros quantitativos que melhor avaliaram o comportamento das espécies nas calçadas foram: altura da árvore ou porte, altura de bifurcação, CAP (circunferência à altura do peito) e diâmetro de copa porque podem ser facilmente correlacionados com os componentes do ambiente urbano.

Os parâmetros qualitativos que melhor avaliaram o comportamento das espécies nas calçadas foram: forma da copa, condição da raiz, brotação no tronco ou na raiz e 
alinhamento do tronco porque refletem tanto as condições ambientais como o manejo das árvores.

As especificações de plantio relativas a largura de calçada, distância de meio-fio e espaçamento foram condizentes com as características das espécies. O maior problema do planejamento foi a desconsideração do porte das árvores com a fiação aérea.

A espécie melhor avaliada foi Clethra scabra $\left(1^{\circ}\right)$, enquanto que as demais foram assim classificadas: $2^{\circ}$ - Aleurites fordii, $3^{\circ}$ - Holocalyx balansae, $4^{\circ}$ - Jacaranda puberula e Michelia champaca, $5^{\circ}$ - Vochysia bifalcata e $6^{\circ}$ - Aspidosperma olivaceum e Citharexylum myrianthum.

\section{REFERÊNCIAS}

AMBIENTE

BRASIL.

Urbano.

Disponível

em:

http://ambientes.ambientebrasil.com.br/urbano.html. Acesso em: 8 agosto 2009.

BACKES, P.; IRGANG, B. Mata Atlântica: as árvores e a paisagem. Porto Alegre: Editora Paisagem do Sul, 2004. 396p.

BIONDI, D. Plantas invasoras na arborização urbana e paisagismo. In: MACEDO, J.H.P.; BREDOW, E.A. Princípios e rudimentos de controle biológico de plantas - Coletânea. Curitiba: FUPEF, 2004. p.03-09.

BIONDI, D.; ALTHAUS, M. Árvores de Rua de Curitiba - Cultivo e Manejo. Curitiba: FUPEF, 2005. 177p.

BIONDI, D.; LEAL, L. Comportamento silvicultural de espécies nativas em viveiro de espera para uso potencial em arborização de ruas. Scientia Forestalis, v.37, n.83, p.313 - 319, 2009a.

BIONDI, D.; LEAL, L. Introducción de Allophylus edulis (A. St Hill, Cambess. \& A.Juss.) Radlk. en la arborización de calles de Curitiba,PR - especie nativa de la Floresta Ombrófila Mista.. In: Congresso Forestal Mundial, XIII, 2009, Buenos Aires. Anais..., Buenos Aires: FAO, 2009b. p.10.

CARVALHO, P. E. R. Espécies florestais brasileiras: recomendações silviculturais, potencialidades e uso da madeira. Colombo; CNPF-Florestas, Embrapa, 1994. 
CAZETTA, E.; GALETTI, M. Ecologia das ervas-de-passarinho. Ciência Hoje, v. 33, n. 194, p. $72-74,2003$.

CEMIG. Manual de Arborização. Belo Horizonte, 1996. 40p.

CEMIG. Manual de Arborização. Belo Horizonte, [s.d.]. 22p.

COBALCHINI, J. I. Critérios para a escolha de espécies utilizadas na arborização urbana viária. In: MACEDO, J.H.P.; BREDOW, E.A. Princípios e rudimentos de controle biológico de plantas - Coletânea. Curitiba: FUPEF, 2004. p.11-13.

ELEKTRO - Eletricidade e Serviços S.A. Guia de Arborização. São Paulo, 2002, 28p.

GERHOLD, H. D.; SALKSTEDER, C. J. Betters ways of selecting trees for urban plantings. Journal of Arboriculture, v.8, n.6, 1982. p.145-153.

GLUFKE, C. Espécies florestais recomendadas para recuperação de áreas degradadas. Porto Alegre, Fundação Zoobotânica do Rio Grande do Sul, 1999. 48p.

HEINDEN, G.; BARBIERI, R. L.; STUMPF, E. R. T. Considerações sobre o uso de plantas ornamentais nativas. Revista Brasileira de Horticultura Ornamental, Campinas, v.12, n.1, p.2-7, 2006.

IPPUC - Instituto de Pesquisa e Planejamento Urbano de Curitiba. Curitiba em dados $2006 . \quad$ Disponível em: <http://ippucnet.ippuc.org.br/bancodedados/curitibaemdados/curitiba_em_dados_pesquisa.a sp>. Acesso em: 28/07/2007.

JBRJ - Jardim Botânico do Rio de Janeiro. Lista de mudas disponíveis - Jardim Botânico do Rio de Janeiro. Disponível em: < http://www.jbrj.gov.br/pesquisa/horto/mudas.htm>. Acesso em: 19/08/2009.

LORENZI, H. Árvores brasileiras: manual de identificação e cultivo de plantas arbóreas nativas do Brasil. Nova Odessa: Editora Plantarum, 1992. 
LORENZI, H. Árvores brasileiras: manual de identificação e cultivo de plantas arbóreas nativas do Brasil. 2 ed. Vol.2. Nova Odessa: Editora Plantarum, 1998.

LORENZI, H.; SOUZA, H. M.; TORRES, M. A; BACHER, L. B. Árvores exóticas no Brasil: madeireiras, ornamentais e aromáticas. Nova Odessa: Instituto Plantarum, 2003.

MILANO, M. S.; DALCIN, E. Arborização de vias públicas. Rio de Janeiro: Light, 2000. $226 p$.

PARON, M.E.; SIQUEIRA, J. O.; CURI, N.; VALE, F. R. Crescimento da copaíba e guatambú em resposta a fungo micorrízico, superfosfato, nitrogênio e fumigação do solo. Disponível em: < $\quad$ em $\quad$ http://www.dcf.ufla.br/cerne/artigos/16-0220098569v2_n2_artigo\%2002.pdf>. Acesso em: 2 agosto 2009.

PHILLIPS, L. E. Urban tree: guide for selection, maintenance and master planning. New York: McGraw-Hill, 1993.

QUEIROZ, P. Se essa rua fosse minha... - Subsídios para o planejamento participativo da arborização de ruas da cidade de Curitiba de Curitiba - PR. 110 f. Monografia (Curso de Especialização em Paisagismo) - Centro de Ciências Exatas e de Tecnologia da Pontifícia da Universidade Católica do Paraná, Curitiba, 2001.

RODERJAN, C. V.; BARDDAL, M.L. Arborização de ruas de Curitiba-PR - Guia prático para a identificação das espécies. Curitiba: FUPEF, 1998.

SÃO PAULO. Secretaria Municipal do Verde e do Meio Ambiente. Manual técnico de arborização urbana. São Paulo: Prefeitura do Município de São Paulo, 2005. 45p.

TATTAR, T. A. Diseases of Shade Trees. New York: Academic Press, 1978. 361 p.

VIEIRA, C. H. S. D. Estudo da dinâmica da cobertura vegetal de Curitiba/PR com o uso de imagens digitais. 165 f. Dissertação (Mestrado em Engenharia Florestal) - Setor de Ciências Agrárias, Universidade Federal do Paraná, Curitiba, 2006. 